Supporting Information for

\title{
Nitrosonium $\left(\mathrm{NO}^{+}\right)$Complexes of Resorc[4]arenes: Spectral, Kinetic and Theoretical Studies
}

\author{
Bruno Botta*a, Ilaria D'Acquarica ${ }^{\mathrm{a}}$, Giuliano Delle Monache ${ }^{\mathrm{a}}$, Laura Nevola ${ }^{\mathrm{a}}$, \\ Danila Tullo ${ }^{\mathrm{a}}$, Franco Ugozzoli ${ }^{\mathrm{b}}$, Marco Pierini* ${ }^{\mathrm{a}}$ \\ ${ }^{a}$ Dipartimento di Studi di Chimica e Tecnologia delle Sostanze Biologicamente Attive, \\ Università "La Sapienza", P.le A. Moro 5, 00185 Roma, Italy \\ ${ }^{\mathrm{b}}$ Dipartimento di Chimica Generale ed Inorganica, Chimica Analitica, Chimica Fisica, \\ Università di Parma, Parco Area delle Scienze 17/a, 43100 Parma, Italy
}

Computational methods

S2

Kinetic determinations

Figures 1S-7S

S4-S8

Re-assignment of the conformation of resorc[4]arene 3 by X-Ray analysis

References

$\mathrm{S} 12$

Total: 12 pages, 8 Figures, 2 Tables. 


\section{Computational Methods}

All the structures of resorcarenes and of their complexes with the $\mathrm{NO}^{+}$cation were built and optimized by means of the computer program SPARTAN 04 (Wavefunction Inc. 18401 Von Karman Avenue, Suite 370 Irvine, CA 92612) running on a PC equipped with Intel Pentium 4, CPU 3.40 GHz,

2 GB of RAM and OS Windows 2000 Professional. Owing to the quite large size of resorcarenes structure the not too much computationally expensive semiempirical method at the AM1 approximation level was used in calculations. Determinations of energy and geometry of all the complexes formed between hosts $\mathbf{1}, \mathbf{2}$ and $\mathbf{3}$ and $\mathrm{NO}^{+}$were performed without the presence of the $\mathrm{BF}_{4}{ }^{-}$counterion. In all cases, a quite large number of different relative orientations of guest and host (from 10 to 18) were considered in calculations, with $\mathrm{NO}^{+}$both inside and outside the resorcarene skeleton. Further optimizations were also performed on all the $\mathbf{2}-\mathrm{NO}^{+}$geometries in the presence of the $\mathrm{BF}_{4}{ }^{-}$counterion, placed in several positions surrounding to $\mathrm{NO}^{+}$. Simulations of both UV-visible spectra and molecular dynamic were performed by the computer program HyperChem ${ }^{\mathrm{TM}}$ Professional for Windows OS, release 7.5. Electronic spectra were carried out by semiempirical calculation with ZINDO/s Hamiltonian. Molecular dynamic simulations were performed by molecular mechanics calculations (MM+ force field), with the electrostatic contributions evaluated employing atomic charges coming from semiempirical AM1 optimizations. Other set options for the same simulations were: heat time 1ps, run time $3 \mathrm{ps}$, cool time $2 \mathrm{ps}$, step size $0.001 \mathrm{ps}$, starting temperature $0{ }^{\circ} \mathrm{K}$, simulating temperature variable from 280 to $300{ }^{\circ} \mathrm{K}$, final temperature $0{ }^{\circ} \mathrm{K}$, temperature step $10^{\circ} \mathrm{K}$, constant temperature, bath relaxation time $0.1 \mathrm{ps}$, permittivity 1 . 


\section{Kinetic determinations}

All kinetic data, composed by set of absorbance values recorded as a function of time at a established wavelength, were processed by non-linear curve fitting analysis. The data related to a single kinetic step were interpolated employing the following equation describing a first order reversible process:

$$
\mathrm{P}^{\max } \times\left(\mathrm{P}^{\max }-\mathrm{P}^{\min }\right) \mathrm{e}^{-k v \times t}
$$

where $t$ is the elapsed time, $k_{v}$ is the apparent first order rate constant of the reversible process, $\mathrm{P}^{\min }$ and $\mathrm{P}^{\mathrm{max}}$ are the initial and final absorbance values at zero and $\infty$ time (achieved plateau), respectively. 

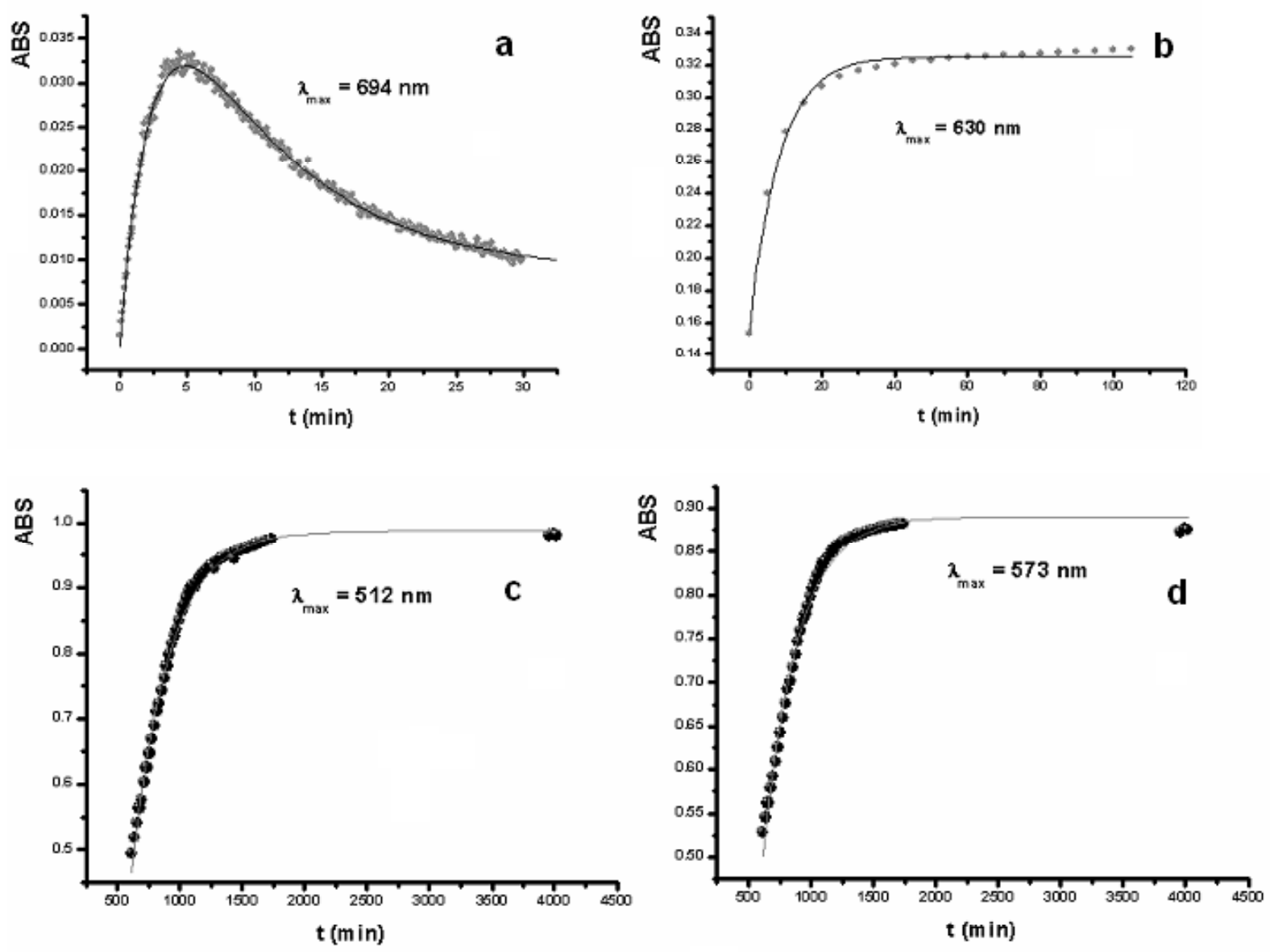

Figure 1S. Non-linear curve fitting analysis (full lines) of the visible spectral data relative to the 1-NO adducts formation recorded in the LEB region as a function of time (full circles). Plots a) and b): absorbance variations at $\lambda_{\max }=694 \mathrm{~nm}$ and $\lambda_{\max }=630 \mathrm{~nm}$, respectively, selected by the spectral ensemble reported in Figure $1 \mathrm{~b}$ (see text). Plots c) and d): absorbance variation at $\lambda_{\max }=512 \mathrm{~nm}$ and $\lambda_{\max }=573 \mathrm{~nm}$, respectively, selected by the spectral ensemble reported in Figure 1c (see text). 


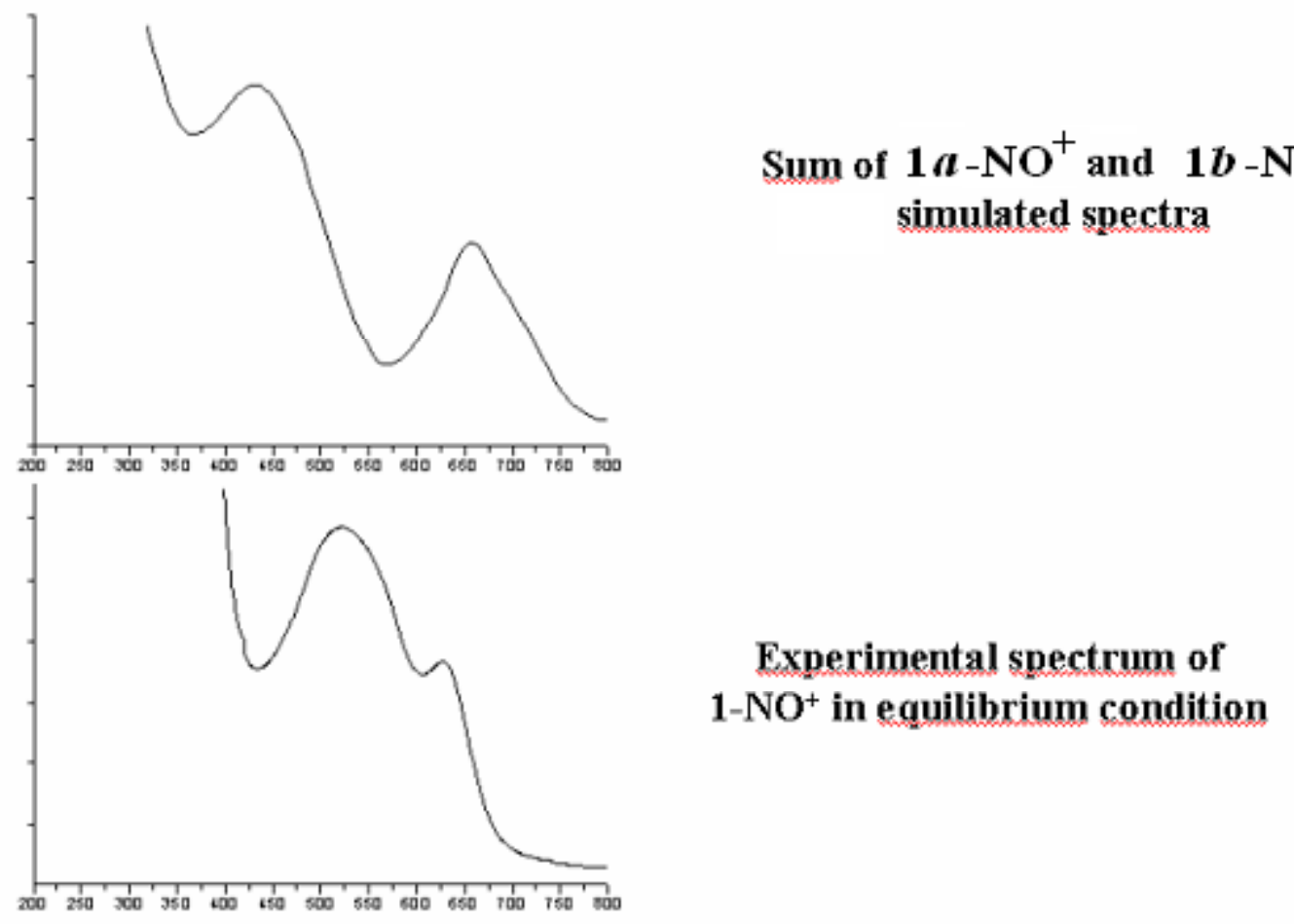

Figure 2S. Calculated (top) and experimental (bottom) UV-visible spectra of a solution containing 1$\mathrm{NO}^{+}$adducts.
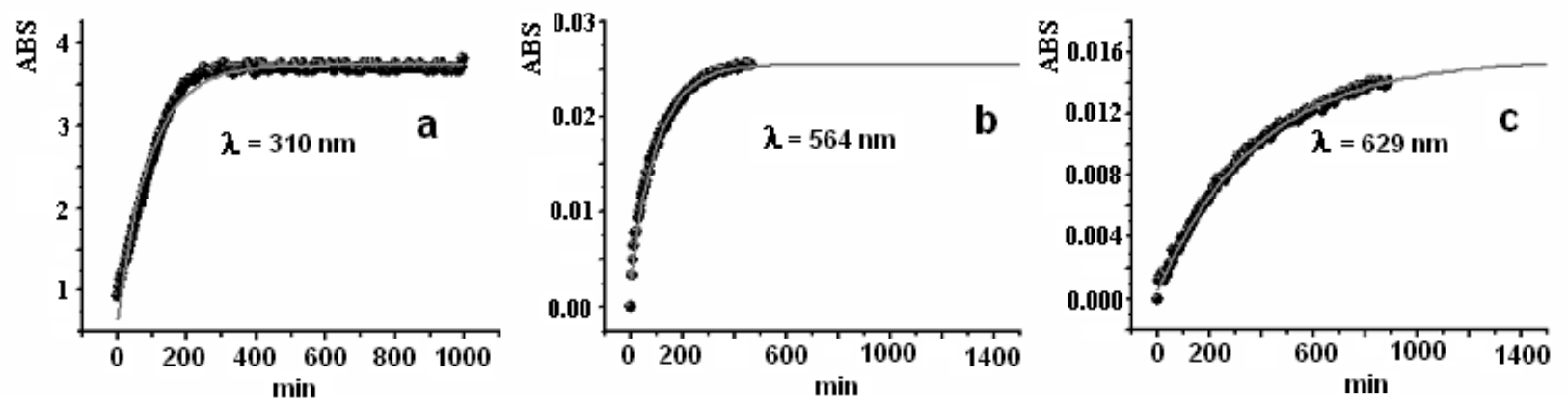

Figure 4S. Non-linear curve fitting analysis (full lines) of the visible spectral data relative to the $2-\mathrm{NO}^{+}$ adducts formation recorded in the regions HEB (plot a, $\lambda_{\max }=310 \mathrm{~nm}$ ) and LEB (plots $\mathrm{b}$ and $\mathrm{c}, \boldsymbol{\lambda}_{\max }=$ $564 \mathrm{~nm}$ and $\lambda_{\max }=629 \mathrm{~nm}$, respectively,) as a function of time (full circles). 


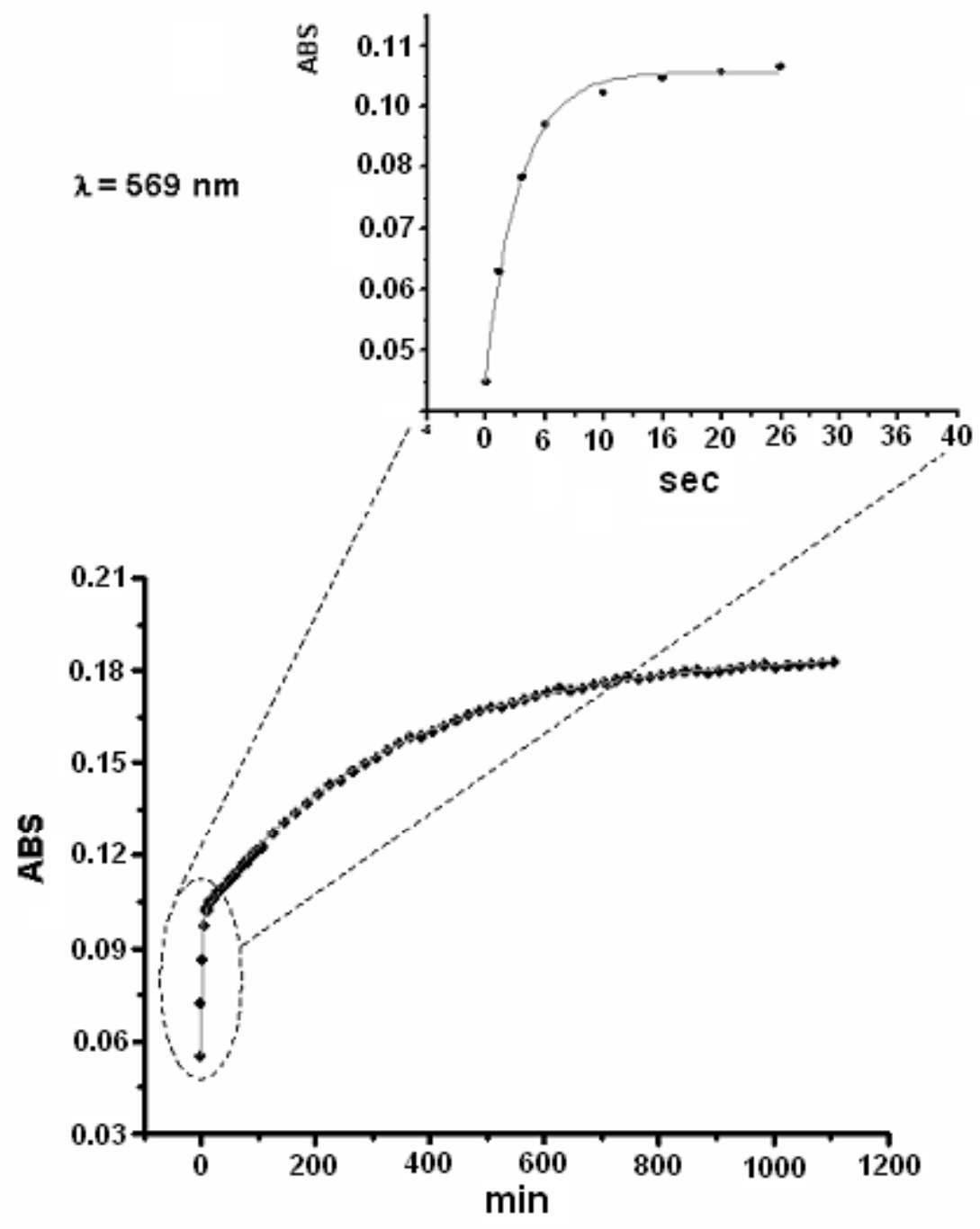

Figure 5S. Non-linear curve fitting analysis (full lines) of the visible spectral data relative to the 3-NO ${ }^{+}$ adducts formation recorded at $\lambda_{\max }=569 \mathrm{~nm}$ as a function of time (full circles). The plot shows two consecutive steps of increasing absorbance, the first (completed by $20 \mathrm{sec}$, as visible in the magnified portion reported in the top of the picture) much faster than the second one. 


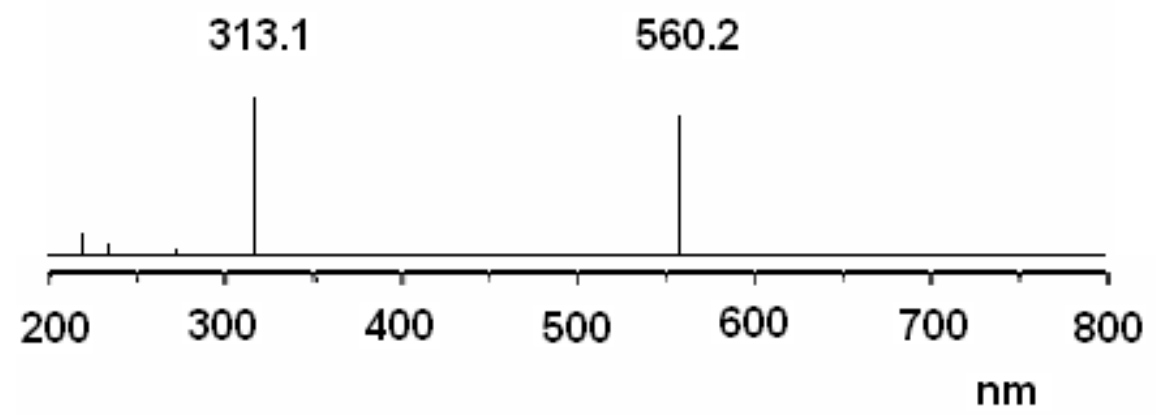

Figure 6S. Simulated UV-visible spectrum of $3 a-\mathrm{NO}^{+}$.
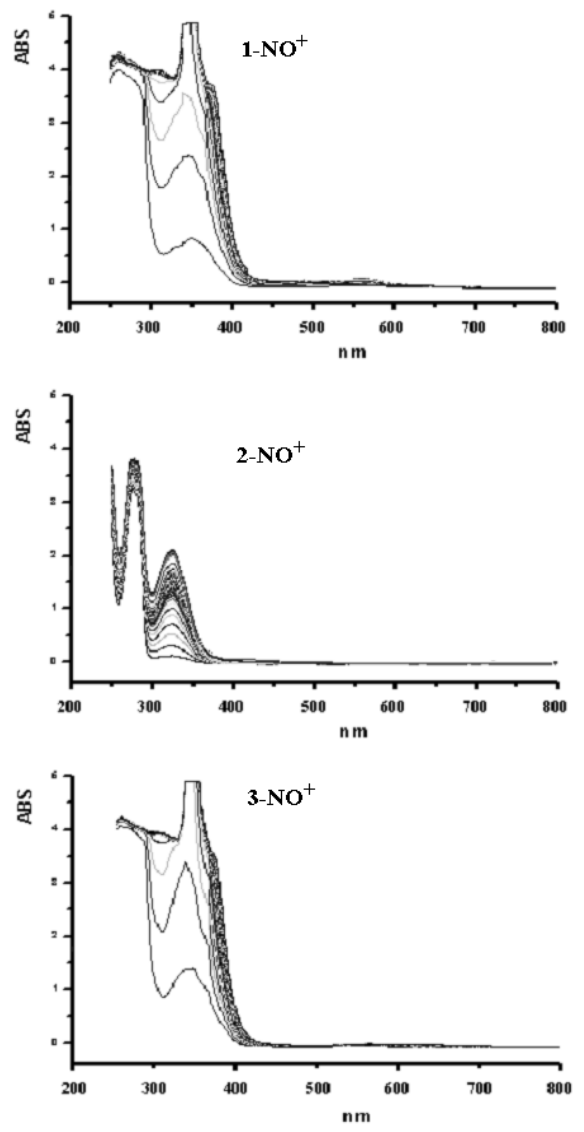

ST 
Figure 7S. Comparison of experimental superimposed UV-visible spectra recorded as a function of time of chloroform solutions containing $\mathbf{1 - \mathrm { NO } ^ { + }}$ (top), $\mathbf{2}-\mathrm{NO}^{+}$(middle), and $\mathbf{3}-\mathrm{NO}^{+}$(bottom) forming complexes at a host-to-guest molar ratio of 10 . 


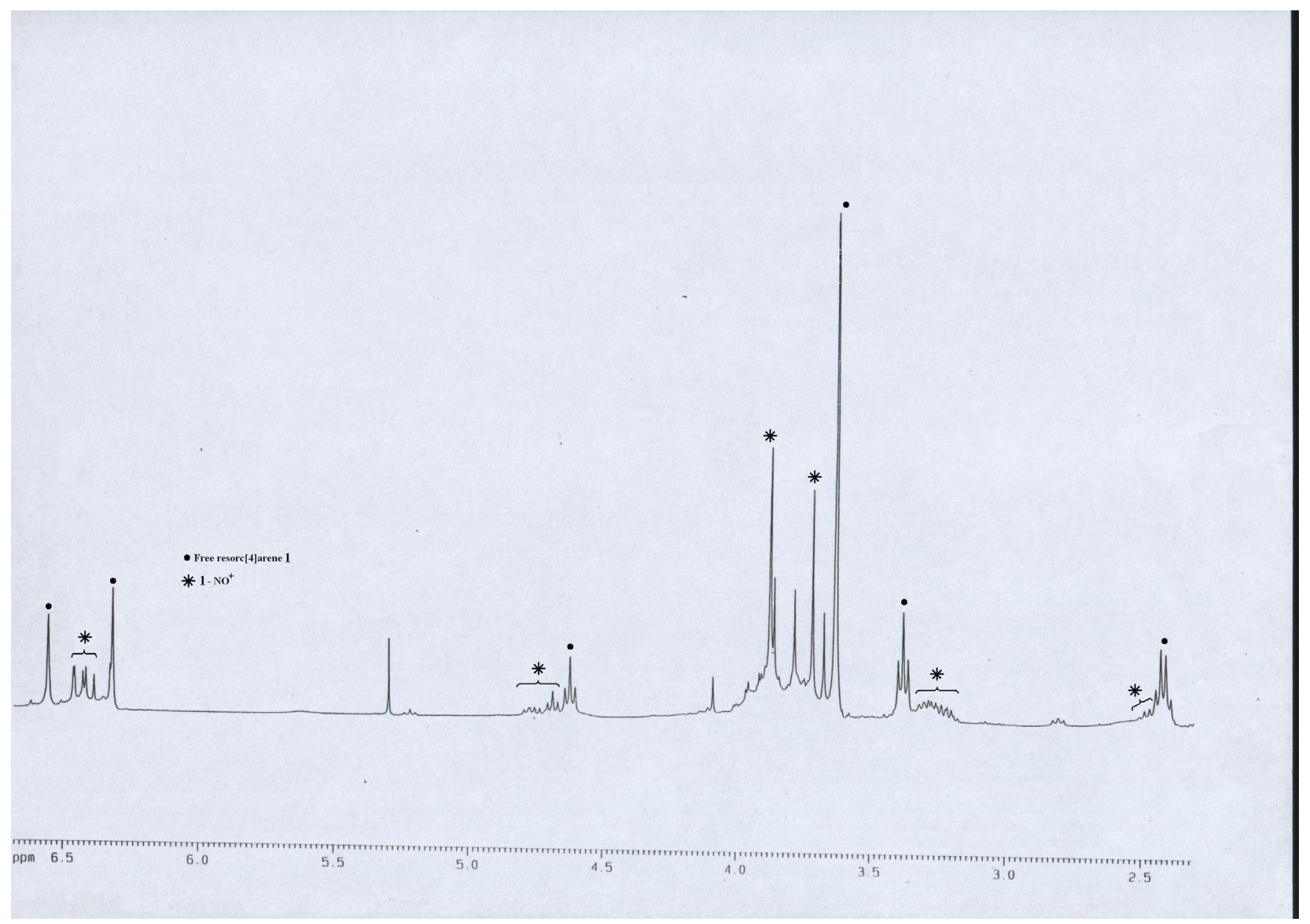

Figure 3S. ${ }^{1} \mathrm{H}$ NMR spectrum of complex $1-\mathrm{NO}^{+}: \bullet=$ free resorc[4]arene $\mathbf{1} ; \boldsymbol{\sim}=$ complex $1-\mathrm{NO}^{+}$. 


\title{
Re-assignment of the conformation of resorc[4]arene 3
}

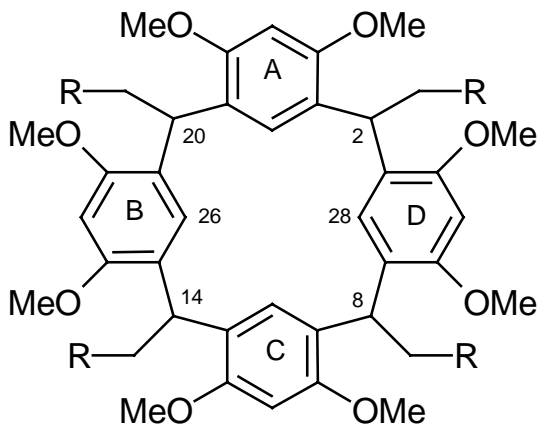

\author{
$\mathrm{R}$ \\ $1 \mathrm{CH}_{2} \mathrm{Br}$ (cone) \\ 2 COOEt (cone) \\ 3 COOEt (chair)
}

The distribution pattern of the signals in ${ }^{1} \mathrm{H}$ and ${ }^{13} \mathrm{C}$ NMR spectra of resorc[4]arene 3 (2 signals each for $\mathrm{H}_{\mathrm{i}}, \mathrm{H}_{\mathrm{e}}$ protons and the methoxyl groups) suggested either a $C_{2 h}$ (flattened partial cone 2) or a $D_{2 d}$ (1,3-alternate) symmetry; the latter was chosen on the basis of the DIF NOE experiments and Molecular Modeling calculations, ${ }^{1 \mathrm{~s}}$ without taking into account the diagnostic highfield chemical shift of the $\mathrm{H}_{\mathrm{ih}}$ protons $(\mathrm{H}-26, \mathrm{H}-28)$, deshielded by the adjacent aromatic B and D rings. When we obtained recently a suitable crystal of $\mathbf{3}$, the X-Ray analysis showed, however, the pseudo-centrosymmetric molecular structure of Figure 8S. For a complete and unequivocal description of the obtained conformation of $\mathbf{3}$ we resorted again to the Symbolic Representation, originally introduced to describe the conformation of calixarenes ${ }^{2 s}$ and recently used by us for cyanoresorc[5]arenes. ${ }^{3 s}$ In this case, to account for the mutual orientations between adjacent aromatic rings, we assumed as $\phi$ and $\chi$ the two torsion angles $1-2-3-4$ and 2-3-4-5, respectively (see Figure $8 \mathrm{Sb}$ ). The calculated values, collected in Table $1 \mathrm{~S}$, lead to the $C_{1}+-,+-,-+,-+$ Symbolic Representation of the molecular conformation of the macrocycle. The conformation has been defined as flattened partial cone 2 in our previous work on amidoresorc[4]arenes, ${ }^{4 \mathrm{~s}}$ or, more simply, as chair in heptanal and decanal derivatives. ${ }^{5 \mathrm{~s}}$ 
Table 1S. Conformational parameters ${ }^{3 \mathrm{~s}} \phi$ and $\chi\left(^{\circ}\right)$ for the molecular structure of $\mathbf{3}$ in the solid state.

\begin{tabular}{|c|c|c|}
\hline Rings & $\phi^{[\mathrm{a}]}$ & $\chi$ \\
\hline A-B & $153(1)$ & $-78(1)$ \\
\hline B-C & $79(1)$ & $-153(1)$ \\
\hline C-D & $-147(1)$ & $83(1)$ \\
\hline D-A & $-82(1)$ & $146(1)$ \\
\hline
\end{tabular}

${ }^{[a]}$ Estimated standard deviations (SD) reported in parentheses were obtained from geometrical calculations on the X-ray crystal structure.

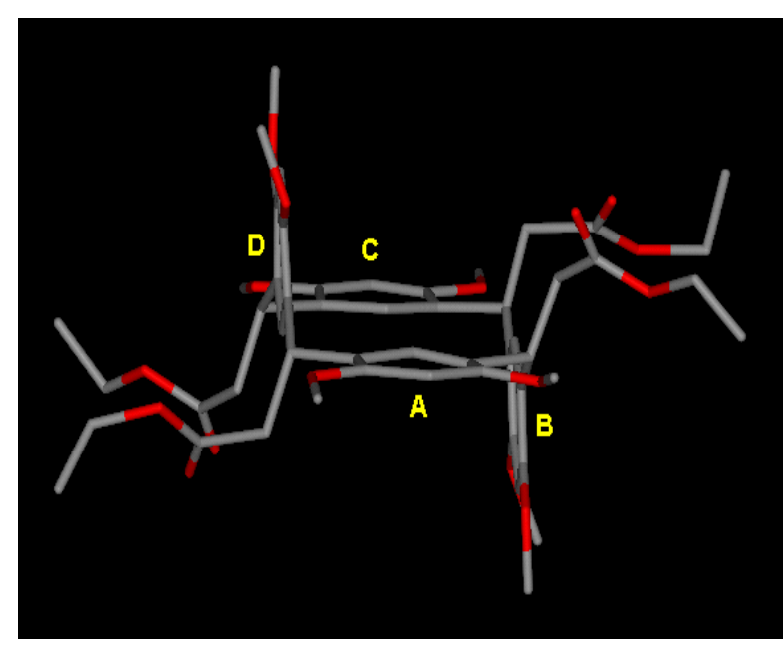

(a)

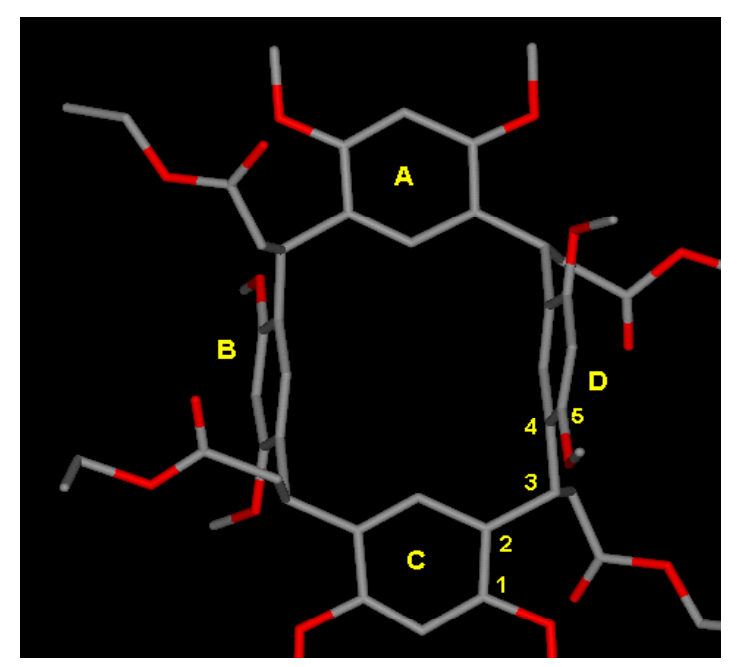

(b)

Figure 8S. Stick views of the molecular structure of compound 3. Colours are as follows: C, grey, O, red. Hydrogen atoms were omitted for clarity.

Crystal data, experimental details for data collection and structure refinement are reported in Table 2S. Intensity data and cell parameters were recorded at room temperature $\left(293{ }^{\circ} \mathrm{K}\right)$ on a Siemens AED diffractometer using graphite monochromated $\mathrm{Cu}-\mathrm{K}_{\alpha}$ radiation. The intensities were corrected for Lorentz, polarization and absorption effects. This structure was characterized by poor diffraction, and several data collections carried out with different samples obtained from different crystallization methods always gave the same results. The structure was solved by Direct methods using SIR2004 ${ }^{6 s}$ and refined on $\mathrm{F}_{\mathrm{o}}{ }^{2}$ by full-matrix least-squares procedures, using SHELXL-97. ${ }^{7 \mathrm{~s}}$ One ethyl acetate 
solvent molecule was found in the crystal lattice. The structure of the macrocycle is pseudocentrosymmetric. The presence of the ethyl acetate solvent lead to the $P 1$ space group instead of $P-1$. All the non-hydrogen atoms were refined with anisotropic atomic displacements, with the exception of the atoms of the ethyl acetate. The hydrogen atoms were included in the refinement at idealized geometry (C-H 1.0 $\AA$ ) and refined "riding" on the corresponding parent atoms. Molecular geometry calculations were carried out using the PARST97 program. ${ }^{8 \mathrm{~s}}$

Table 2S. Crystal data, data collection and refinement parameters for $\mathbf{3}$

\begin{tabular}{|c|c|}
\hline Chemical formula & $\mathrm{C}_{52} \mathrm{H}_{64} \mathrm{O}_{16} \cdot \mathrm{C}_{4} \mathrm{H}_{8} \mathrm{O}_{2}$ \\
\hline Formula weight & 1032.47 \\
\hline Crystal system $\left[\mathrm{mm}^{3}\right]$ & Triclinic \\
\hline Space group & $P 1$ \\
\hline$a[\AA]$ & 12.264(9) \\
\hline$b[\AA]$ & $14.080(2)$ \\
\hline$c[\AA]$ & $8.444(1)$ \\
\hline$\alpha\left[^{\circ}\right]$ & $101.07(1)$ \\
\hline$\beta\left[^{\circ}\right]$ & $88.62(1)$ \\
\hline$\gamma\left[^{\circ}\right]$ & $108.56(1)$ \\
\hline$V\left[\AA^{3}\right]$ & $1355(1)$ \\
\hline$Z$ & 1 \\
\hline$\rho_{\text {calc. }}\left[\mathrm{g} \mathrm{cm}^{-3}\right]$ & 1.266 \\
\hline$\mu\left(\mathrm{mm}^{-1}\right)$ & $1.158\left(\mathrm{Cu}-\mathrm{K}_{\alpha}\right)$ \\
\hline \multicolumn{2}{|l|}{ Data Collection and Refinement } \\
\hline $2 \theta$ max for data collection $\left[^{\circ}\right]$ & 140.42 \\
\hline Temperature $[\mathrm{K}]$ & 293 \\
\hline Data collected $(h, k, l)$ & $(-14,-17,0)$ to $(14,16,10)$ \\
\hline Total reflections & 5366 \\
\hline Unique reflections & $5366\left(\mathrm{R}_{\mathrm{int}}=0\right)$ \\
\hline Observed reflections & $1935[\mathrm{Fo}>4.0 \sigma(\mathrm{Fo})]$ \\
\hline Data/ restraints / parameters & $5366 / 48 / 640$ \\
\hline Goodness-of-fit on $F^{2[\mathrm{a}]}$ & 0.821 \\
\hline Final R indices (obs. data) ${ }^{[\mathrm{b}]}$ & $R_{1}=0.0795, w R_{2}=0.1976$ \\
\hline $\mathrm{R}$ indices (all data) ${ }^{[\mathrm{b}]}$ & $R_{1}=0.201, w R_{2}=0.2526$ \\
\hline Largest diff. peak and hole $\left[\mathrm{e} \AA^{-3}\right]$ & $0.47 /-0.29$ \\
\hline
\end{tabular}

${ }^{[a]}$ Goodness-of-fit $\mathrm{S}=\left[\Sigma w\left(F_{\mathrm{O}}{ }^{2}-F \mathrm{c}^{2}\right)^{2} /(n-p)\right]^{1 / 2}$, where $n$ is the number of reflections and $p$ the number of parameters. ${ }^{[\mathrm{b}]} R_{l}=\Sigma\|\mathrm{Fo}|-| \mathrm{Fc}\| / \Sigma|\mathrm{Fo}|, w R_{2}=\left[\Sigma w\left(\mathrm{Fo}^{2}-\mathrm{Fc}^{2}\right)^{2} / \Sigma w \mathrm{Fo}^{4}\right]^{1 / 2}$. 


\section{References}

(1s) Botta, B.; Di Giovanni, M. C.; Delle Monache, G.; De Rosa, M. C.; Gács-Baitz, E.; Botta, M.;

Corelli, F.; Tafi, A.; Santini, A., Benedetti, E.; Pedone, C.; Misiti, D. J. Org. Chem. 1994, 59, 1532-1541.

(2s) Ugozzoli, F.; Andreetti, G. D. J. Inclusion Phenom. Mol. Recognit. 1992, 13, 337-348.

(3s) D’Acquarica, I.; Nevola, L.; Delle Monache, G.; Gács-Baitz, E.; Massera, C.; Ugozzoli, F.; Zappia, G.; Botta, B. Eur. J. Org. Chem. 2006, 3652-3660.

(4s) Botta, B.; Delle Monache, G.; Salvatore, P.; Gasparrini, F.; Villani, C.; Botta, M.; Corelli, F.; Tafi, A.; Gács-Baitz, E.; Santini, A., Carvalho, C. F.; Pedone, C.; Misiti, D. J. Org. Chem. 1997, 59, 932-938 and Supporting Information.

(5s) Abis, L.; Dalcanale, E.; Du Vosel, A.; Spera, S. J. Org. Chem. 1988, 53, 5475 -5479.

(6s) Burla, M. C.; Calandro, R.; Cavalli, M.; Carrozzini, B.; Cascarano, G. L.; De Caro, L.; Giacovazzo, C.; Polidori, G.; Spagna, R. J. Appl. Cryst. 2005, 38, 1381-1388.

(7s) Sheldrick, G. M. SHELXL-97, Program for Crystal Structure Refinement, University of Göttingen, 1997; http://shelx.uni-ac.gwdg.de/shelx/index.html.

(8s) Nardelli, M. PARST97, updated version of PARST95, J. Appl. Crystallogr. 1995, 28, 659. 